\title{
O desenvolvimento profissional e humano de professores no contexto da educação inclusiva: reflexões embasadas na perspectiva histórico-cultural
}

\section{The professional and human development of teachers in the context of inclusive education: reflections based on the cultural and historical approach}

Cibele Moreira Monteiro' (USF/Unifei) Ana Paula de Freitasii (USF)

\begin{abstract}
Resumo: Este artigo intenciona refletir acerca do desenvolvimento docente à luz da perspectiva histórico-cultural, tomando como lócus analítico uma experiência formativa com foco na educação inclusiva realizada com um grupo de professores da educação básica. A análise de relatos escritos por esses professores permitiu encontrar indícios de seu processo de desenvolvimento profissional e humano, como reflexo da ação formativa proposta.

Palavras-chave: Perspectiva histórico-cultural; desenvolvimento humano; desenvolvimento do adulto; formação docente; educação inclusiva.
\end{abstract}

\begin{abstract}
This paper intends to reflect on teacher development in light of the cultural and historical approach, taking as an analytical locus an educational experience focusing on inclusive education with a group of elementary school teachers. The analysis of the teacher's written reports allowed us to find evidence of their professional and human development process as a reflection of the proposed training activities.
\end{abstract}

Keywords: Cultural and historical approach; human development; adult development; teacher training; inclusive education.

Introdução

A implantação de uma política educacional pública sob a perspectiva da inclusão e do compromisso da educação como direito social (BRASIL, 1996, 2008) tem permitido o acesso de alunos com deficiência à rede regular de ensino. No entanto, a garantia de acesso 
não tem resultado na garantia de aprendizagem e de desenvolvimento desses alunos. Estudos têm apontado para o desafio posto aos professores das escolas regulares para realizar uma mediação pedagógica que assegure a apropriação do conhecimento escolar aos alunos com deficiência (DAINEZ; SMOLKA, 2019; PADILHA, 2018; PLETSCH, 2014).

Para mudar esse cenário, é essencial que se invista na formação docente. Porém, muitas propostas nessa área não têm conseguido contribuir para a superação dos desafios enfrentados no cotidiano escolar. Michels (2011, p. 229), ao analisar as iniciativas destinadas à formação de professores para o trabalho escolar com alunos com deficiência em sete municípios de Santa Catarina, observa que "há, ainda, uma preponderância nas formações de um modelo que secundariza o pedagógico e privilegia o médico-psicológico".

Garcia (2013) e Kassar (2014) também realçam as limitações e as precariedades da formação de professores na área da educação especial na perspectiva inclusiva. Conforme afirma Garcia (2013, p. 116), são comuns propostas esvaziadas "de base teórica e de conteúdo pedagógico". Predominam, segundo Kassar (2014), cursos de formação massificados, que não promovem reflexões aprofundadas nem questionamentos por parte dos professores. Desse modo, esses profissionais não encontram, nesses cursos, oportunidades de transformação, de reelaboração de concepções e percepções.

A superficialidade da formação docente acaba aprisionando os professores nas "armadilhas de uma perspectiva inclusiva que abre mão da aprendizagem dos alunos, que os generaliza e massifica na forma de propor os serviços" (GARCIA, 2013, p. 116). Para que essas armadilhas possam ser superadas e a educação inclusiva passe a ser caracterizada pela efetivação de práticas pedagógicas que visem garantir a aprendizagem de todos os alunos, é necessário que se busquem processos de formação docente capazes de promover o desenvolvimento dos professores.

Com base na análise de uma experiência formativa com foco na educação inclusiva realizada com um grupo de professores da educação básica e dos relatos escritos por eles, temos como objetivo neste artigo refletir sobre o desenvolvimento do professor à luz da perspectiva histórico-cultural, a partir dos estudos de Vigotski ${ }^{1}$. A experiência formativa a que nos referimos ocorreu no âmbito de um projeto extensionista do qual participam as autoras deste texto.

\footnotetext{
${ }^{1} \mathrm{O}$ nome deste autor aparece na literatura com diferentes grafias. Neste trabalho, optamos por "Vigotski", mas, nas indicações bibliográficas, preservamos a grafia original adotada em cada material citado.
}

Eutomia, Recife, 27(1): 238-257, Out. 2020 
Organizamos este trabalho em mais duas seções, além das "Considerações finais". Na primeira delas, relatamos o encontro de formação docente realizado. Na segunda, refletimos sobre as possibilidades de desenvolvimento profissional e humano de professores com base nos fundamentos teóricos da perspectiva histórico-cultural, entrelaçando nossas reflexões à análise dos relatos escritos pelos participantes do encontro formativo.

\section{Formação docente: relato de uma prática formativa no contexto da educação inclusiva}

O planejamento e o desenvolvimento de atividades de formação docente exigem que sejam consideradas as especificidades do contexto em que atuam os professores. Como afirma Gatti (2017, p. 722), "pensar e fazer a formação de professores envolve considerar condições situacionais e conscientizar-se das finalidades dessa formação, considerar os porquês, o para quê e o para quem é realizada essa formação, assumindo compromissos éticos e sociais".

A análise das motivações e dos objetivos da formação docente, bem como das pessoas a quem ela se destina, é essencial para que os resultados das ações desenvolvidas possam impactar a prática educativa da maneira pretendida. Por isso é tão importante conhecer a realidade vivenciada pelos professores nas escolas.

Muitos são os desafios que caracterizam o exercício da docência na contemporaneidade. Entre eles, observamos o movimento de explicitação da diversidade humana. Segundo Gatti (2017, p. 724), "surgem, neste movimento, as diferenças, que passam a ser reconhecidas e consideradas".

Nesse contexto, garantir a aprendizagem e o desenvolvimento de todos os alunos apresenta-se como uma necessidade, porém muitos não sabem o que fazer para que isso se torne realidade. Conforme destaca Garcia (2016), as proposições inclusivas não têm garantido a universalização do ensino no Brasil. Isso também é observado por Laplane (2014, p. 202), que, ao analisar o ingresso e a permanência de alunos com deficiência nas escolas regulares, afirma que a "situação ainda é distante do ideal".

Diante desses problemas, planejamos um projeto extensionista com a finalidade de promover práticas de formação docente que possam contribuir para a efetivação da política de educação inclusiva, considerando a necessidade de garantir a todos os alunos a 
apropriação dos conhecimentos escolares, e não apenas o acesso às escolas regulares. Esse projeto foi estruturado considerando que

[...] a parceria entre universidade-escola, numa perspectiva de trabalho colaborativo, configura-se como uma possibilidade para que sejam discutidas as necessidades concretas do professor em seu fazer pedagógico, levando em consideração suas condições de trabalho e a realidade do contexto no qual atua. (FREITAS; MONTEIRO, 2016, p. 145).

Neste trabalho, abordamos mais especificamente uma das ações integrantes desse projeto de extensão, a qual consistiu em um encontro de formação com foco na educação inclusiva, desenvolvido com 23 professores que atuam nos anos finais do ensino fundamental, no ensino médio e no atendimento educacional especializado de uma escola estadual localizada em uma cidade de médio porte do sul de Minas Gerais, a qual atende cerca de 450 alunos. A realização da ação extensionista nessa instituição deu-se em função de sua tradição no acolhimento de alunos que são o público-alvo da educação especial.

Dividimos os participantes em dois grupos, de acordo com sua disponibilidade de horário. Havia 11 professores no turno da manhã e 12 professores no turno da tarde. Com os dois grupos realizamos as mesmas atividades, totalizando três horas de trabalho com cada um deles.

O encontro de formação foi desenvolvido na perspectiva colaborativa. No início, quando os professores se apresentaram, solicitamos a cada um que expressasse, de maneira sucinta, a primeira ideia que the vinha à mente quando pensava em educação inclusiva. Foram citadas as seguintes palavras ou expressões, sendo algumas delas apresentadas por mais de um professor: "desafio", "novo", "vencer obstáculos", "o discurso não bate com a prática", "utopia", "medo", "tentativas", "diferenças", "necessidade dos alunos", "necessidade de formação dos professores", "necessidade de todos abraçarem a causa", "descobrir como ajudar", "sair da zona de conforto", "respeito", "paciência, carinho e amor", "acolhimento", "superação de preconceitos", "aceitação" e "autoconhecimento". Logo após as falas de todos os participantes, refletimos com eles a respeito das ideias que compartilharam, com a intenção de suscitar questionamentos acerca das concepções de deficiência que as sustentam. 
Posteriormente, apresentamos o vídeo intitulado "Pensar utopicamente a educação" ${ }^{2}$, de aproximadamente 17 minutos, no qual o professor e pesquisador português David Rodrigues aborda a educação inclusiva citando utopias para a educação do futuro e propondo caminhos para que elas sejam alcançadas ${ }^{3}$. Em seguida, organizamos uma roda de conversa para discutir os tópicos abordados no vídeo e relacioná-los ao cotidiano vivenciado pelos docentes na escola. Nesse momento, eles expuseram os desafios enfrentados na busca da escolarização de todos os alunos e as conquistas que já conseguiram observar.

Ao tratarem dos desafios, muitos professores ressaltaram que não se sentem preparados para trabalhar de maneira adequada com os alunos com deficiência por não terem formação específica nessa área. Eles também destacaram que as condições de funcionamento das escolas não contribuem para que os objetivos da educação inclusiva sejam alcançados, uma vez que as turmas costumam ter uma grande quantidade de alunos, o que dificulta o conhecimento das particularidades de cada um deles. Ao abordarem as conquistas já observadas, os docentes realçaram a importância do apoio dos familiares dos alunos e do desenvolvimento de atividades pedagógicas diferentes daquelas que caracterizam os métodos tradicionais de ensino.

Após a realização da roda de conversa, expusemos alguns fundamentos teóricos da perspectiva histórico-cultural do desenvolvimento humano, a fim de que, com base nesse referencial, os professores pudessem refletir sobre os processos de aprendizagem e de desenvolvimento dos alunos. Segundo a perspectiva histórico-cultural, as possibilidades de aprendizagem de um indivíduo não são determinadas por suas características biológicas, uma vez que as funções psíquicas superiores - como a atenção voluntária, a imaginação criadora, a memória lógica, a elaboração conceitual, a vontade, a linguagem, entre outras são externas antes de tornarem-se internas, isto é, desenvolvem-se a partir da interação do indivíduo com os outros (VYGOTSKI, 2012).

Salientamos que a opção pelo trabalho com os fundamentos da perspectiva histórico-cultural se deu pelas contribuições desse constructo teórico para o desenvolvimento de um olhar para os alunos - principalmente aqueles com deficiência -

\footnotetext{
${ }^{2} \mathrm{O}$ vídeo está disponível no seguinte endereço eletrônico: https://www.youtube.com/watch?v=okDL5kxDg_A. Acesso em: 6 fev. 2021.

${ }^{3}$ David Rodrigues trata da utopia como algo que não é real, mas que pode vir a tornar-se realidade.
} 
mais centrado em suas potencialidades do que em suas impossibilidades. Ao entenderem que "o aparato biológico, por si, não define as possibilidades de uma pessoa se desenvolver, pois tal desenvolvimento está arraigado às condições materiais de existência humana" (FREITAS; MONTEIRO; CAMARGO, 2015, p. 28), os professores podem ter condições de compreender que a aprendizagem e o desenvolvimento não são determinados pelo déficit orgânico, mas, sobretudo, pelas oportunidades oferecidas pelo meio sociocultural. Desse modo, eles sentem-se motivados a buscar formas de trabalho sustentadas por práticas sociais e significativas, que viabilizem o desenvolvimento de todos os alunos.

No encontro de formação, ao longo dos relatos orais, dos estudos realizados e das reflexões decorrentes deles, exploramos as três dimensões do trabalho docente identificadas por Fanfani (2007): a técnico-instrumental ou racional, a afetiva ou vocacional e a política. Essas dimensões referem-se, respectivamente, à "racionalidad técnico instrumental del oficio" ${ }^{4}$ (FANFANI, 2007, p. 350), a qual possibilita ao professor ter melhores condições de solucionar "los problemas complejos e inéditos de la enseñanza y el aprendizaje $^{\prime \prime}$ (FANFANI, 2007, p. 350); ao desenvolvimento de uma postura ética, caracterizada pelo "'compromiso', 'respeto' y 'cuidado' por el otro"' ${ }^{6}$ (FANFANI, 2007, p. 349); e ao comprometimento "con la formación de la ciudadanía activa y la construcción de una sociedad más justa, más libre y por lo tanto más 'humana"m7 (FANFANI, 2007, p. 351).

Esclarecemos que, embora essas três dimensões do trabalho docente tenham sido exploradas ao longo do encontro formativo, elas não foram nomeadas durante a realização das atividades nem houve um momento específico para o trabalho com cada uma delas separadamente.

Para encerrar o encontro, solicitamos aos professores que escrevessem um relato a respeito das contribuições resultantes das atividades desenvolvidas. Alguns professores optaram por escrever o texto individualmente e outros, em grupo, totalizando 14 relatos.

\footnotetext{
${ }^{4}[\ldots .$.$] "racionalidade técnico-instrumental da profissão" (tradução nossa).$

${ }^{5}$ [...] "os problemas complexos e inéditos do processo de ensino e aprendizagem" (tradução nossa).

${ }^{6}[\ldots .$.$] "'compromisso', 'respeito' e 'cuidado' pelo outro" (tradução nossa).$

7 [...] "com a formação da cidadania ativa e com a construção de uma sociedade mais justa, mais livre e, portanto, mais 'humana'" (tradução nossa).
} 


\section{Reflexões sobre o desenvolvimento de professores à luz da perspectiva histórico- cultural}

Com base na experiência de formação docente descrita acima, refletimos nesta seção sobre o desenvolvimento profissional e humano de professores à luz da perspectiva histórico-cultural, entrelaçando nossas reflexões à análise dos relatos escritos pelos professores que participaram do encontro formativo com foco na educação inclusiva. Ressaltamos que realizamos a análise dos relatos em consonância com o que propõe o paradigma indiciário. Conforme explica Pino (2005, p. 178, grifo do autor), "procurar indícios implica em optar por um tipo de análise que siga pistas, não evidências, sinais, não significações, inferências, não causas desse processo". Ainda segundo o autor, "a análise de indícios é constituída de atos de interpretação" (PINO, 2005, p. 187, grifos do autor).

Iniciamos nossas reflexões definindo o que é desenvolvimento. De acordo com Oliveira (2004, p. 213), "podemos definir desenvolvimento, sinteticamente, como transformação". Como complementa a autora,

[...] processos de transformação ocorrem ao longo de toda a vida do sujeito e estão relacionados a um conjunto complexo de fatores. Na abordagem histórico-cultural encontramos a postulação do desenvolvimento humano como sendo resultado da interação entre quatro planos genéticos - a filogênese, a ontogênese, a sociogênese e a microgênese. (OLIVEIRA, 2004, p. 213).

Ao tratar da filogênese, entendida como a história da espécie, Vygotski (2012) explica que ela envolve um processo de desenvolvimento biológico por meio do qual as espécies animais evoluíram até o surgimento do Homo Sapiens e também um processo de desenvolvimento histórico por meio do qual o homem primitivo se transformou em um ser dotado de cultura. Como salienta o autor, "ambos procesos, el desarrollo biológico y el cultural de la conducta, están presentes por separado en la filogénesis, son dos líneas independientes de desarrollo" ${ }^{8}$ (VYGOTSKI, 2012, p. 30).

O mesmo não ocorre na ontogênese, que trata da história do homem a partir da concepção até a morte. Conforme esclarece Vygotski (2012, p. 30), na ontogênese as linhas

\footnotetext{
${ }^{8}$ [...] "ambos os processos, o desenvolvimento biológico e o desenvolvimento cultural do comportamento, estão presentes de modo separado na filogênese, são duas linhas independentes de desenvolvimento" (tradução nossa).
} 
de desenvolvimento biológico e de desenvolvimento cultural "aparecen unidas, forman de hecho un proceso único, aunque complejo" ${ }^{\prime 9}$.

Pensar no desenvolvimento cultural implica considerar os fatores sociais, uma vez que "la cultura es un producto de la vida social y de la actividad social del ser humano"10 (VYGOTSKI, 2012, p. 151). Por isso, nas obras vigotskianas é tão destacada a importância do estudo da sociogênese, que explora as especificidades históricas de determinado grupo sociocultural, realçando que o desenvolvimento do ser humano só é possível nas/pelas relações sociais, tendo em vista as dimensões cultural e semiótica do funcionamento humano.

No entanto, isso não implica desconsiderar as particularidades de cada indivíduo e a maneira própria de ele significar suas relações sociais. Consequentemente, é necessário que o estudo do desenvolvimento humano também considere a microgênese, isto é, a história singular de cada pessoa. Esclarecemos, assim como Moura et al. (2016, p. 107), que o termo microgênese "não foi cunhado por Vigotski e sim por Wertsch [...], embora Vigotski tenha feito, ao longo de sua obra, várias menções a esses aspectos de singularidade do sujeito".

O fato de Vigotski ter valorizado os aspectos individuais do desenvolvimento humano é explicitado pelo próprio Wertsch: "Además de la filogénesis, la historia sociocultural y la ontogénesis, otro dominio genético - que yo denominaré 'microgénesis' - ha desempeñado, en ciertas ocasiones, un papel importante en el análisis vygotskyano"11 (WERTSCH, 1988, p. 71). Podemos observar a valorização do nível microgenético, por exemplo, quando Vigotski defende o método instrumental por ele estudar "o processo de desenvolvimento natural e da educação como um processo único", com o objetivo de "descobrir como se reestruturam todas as funções naturais de uma determinada criança em um determinado nível de educação" (VIGOTSKI, 2004, p. 99). Ou, ainda, quando ele se propõe, no estudo do desenvolvimento psíquico, a realçar as minúcias do processo, que são profundamente significativas (VYGOTSKI, 2012).

Ao entendermos desenvolvimento como sinônimo de transformação e compreendermos, por meio da análise dos quatro planos genéticos explorados por Vigotski,

\footnotetext{
9 [...] "aparecem unidas, formam de fato um processo único, embora complexo" (tradução nossa).

${ }^{10}$ [...] "a cultura é um produto da vida social e da atividade social do ser humano" (tradução nossa).

11 "Além da filogênese, da história sociocultural e da ontogênese, outro domínio genético - que eu denominarei 'microgênese' - tem desempenhado, em certas ocasiões, um papel importante na análise vigotskiana." (tradução nossa).
} 
a complexidade dos fatores que interferem no desenvolvimento humano, percebemos que ele ocorre em todas as fases da vida. Portanto, a definição da idade adulta "como sendo um estágio psicológico de estabilidade e ausência de mudanças importantes (quase que excluído, portanto, da própria essência do desenvolvimento) é, claramente, inadequada" (OLIVEIRA, 2004, p. 217).

Aqueles que consideram que a idade adulta é uma fase caracterizada pela ausência de desenvolvimento ignoram que "a maturação biológica [...] não representa a totalidade do desenvolvimento" (OLIVEIRA, 2004, p. 214) e que "es la sociedad y no la naturaleza la que debe figurar en primer lugar como el factor determinante de la conducta del hombre ${ }^{\prime 12}$ (VYGOTSKI, 2012, p. 89). Ao compreendermos a importância dos fatores históricoculturais, sociais e individuais para o desenvolvimento humano, percebemos que as atividades de formação docente podem constituir fontes importantes de desenvolvimento dos professores, na medida em que ocorrem em contextos dinâmicos, mediados semioticamente.

Para refletirmos sobre as possibilidades de desenvolvimento oportunizadas por ações de formação docente, é importante destacarmos o papel que a perspectiva históricocultural atribui aos instrumentos produzidos pelo homem. Vygotski (2012) diferencia os instrumentos técnicos, que são produzidos para agir sobre a natureza, provocando nela transformações, e os signos, considerados instrumentos psicológicos, produzidos para a comunicação e a representação da realidade.

Em consonância com Pino (1995, 2005), empregamos o termo instrumento técnicosemiótico a fim de destacar a ideia de que a atividade humana implica tanto o meio técnico (instrumentos) como o simbólico (signos), os quais constituem os dois mediadores que permitem as relações entre os homens. Para o autor, por meio do instrumento técnico, o homem transforma a natureza da qual ele é parte e, por meio do instrumento psicológico (signo), ele atribui a essa transformação uma significação. Vale destacar ainda que, para Vygotski (2012), a palavra é o signo principal e, por meio dela, nas relações sociais, sentidos são atribuídos às coisas do mundo, àquilo que é dito (ou não dito), às expressões, aos gestos. Desse modo, a significação é "aqui tomada como marcas ou efeitos que se produzem e impactam os sujeitos na relação" (SMOLKA, 2004, p. 43).

\footnotetext{
12 [...] "é a sociedade e não a natureza que deve figurar em primeiro lugar como o fator determinante do comportamento do homem" (tradução nossa).
} 
Observamos que, no encontro de formação docente relatado neste artigo, os instrumentos técnico-semióticos foram utilizados em diferentes momentos e de diferentes maneiras: no compartilhamento oral de concepções acerca da deficiência e do ensino para alunos com deficiência, nos relatos orais de experiências vividas com esses alunos, no vídeo apresentado, nas exposições teóricas e nos relatos escritos pelos professores sobre as contribuições do encontro. Por meio dessas atividades, mediadas pela palavra oral e escrita e pelos recursos tecnológicos, os participantes puderam organizar e exteriorizar seu pensamento, relacionar-se com os outros e conhecer diferentes experiências, conceitos e modos de pensar, tendo a oportunidade de vivenciar um processo de transformação de si mesmos e dos outros.

Nos relatos escritos ao final do encontro ${ }^{13}$, encontramos indícios de que as diferentes atividades caracterizadas pelo uso de instrumentos técnico-semióticos contribuíram para mobilizar o processo de desenvolvimento dos professores e para torná-los conscientes da necessidade de se transformarem:

A palestra e o vídeo exibido possibilitaram uma visão diferenciada e mais ampla sobre o assunto [...]. (Excerto do relato 4).

[O encontro possibilitou] repensar caminhos, paradigmas. (Excerto do relato 1 ).

Vejo que precisamos nos aprofundar cada vez mais no assunto para que a prática seja eficiente no âmbito escolar. Mudança de comportamento é muito importante para que a inclusão realmente aconteça. Os conhecimentos passados são fundamentais para o nosso crescimento. (Excerto do relato 5).

[...] devemos incluir e evoluir, pois só desta forma a teoria amplamente falada pode virar uma realidade que queremos alcançar. (Excerto do relato 11).

Os excertos transcritos realçam que as relações intersubjetivas, mediadas pelos instrumentos técnico-semióticos, possibilitam a reelaboração de conceitos e a ressignificação de experiências. Nas atividades de formação docente,

\footnotetext{
${ }^{13}$ Os relatos foram escritos pelos professores de forma anônima, sendo identificados neste trabalho por números.
}

Eutomia, Recife, 27(1): 238-257, Out. 2020 
[...] as relações significativas que se constituem no coletivo (plano social) levam os participantes (plano individual) a apropriarem-se de novos conhecimentos, reelaborarem conceitos que estavam estabilizados e, deste modo, em um processo dinâmico, dialético, produzirem novos sentidos para seus saberes e práticas pedagógicas. (FREITAS; MONTEIRO, 2016, p. 146).

A relação entre o social e o individual no processo de apropriação de conhecimentos também é destacada por Pino (1995, p. 33), segundo o qual, "na perspectiva históricocultural, a mediação da dupla instrumentalidade, técnica e semiótica, confere [...] ao ato de conhecer o caráter de um ato, ao mesmo tempo, singular - próprio de cada sujeito - e social - resultado da participação dos outros". A importância do outro para a internalização de novos conhecimentos, para a reelaboração de conceitos e para a ressignificação de saberes e experiências leva-nos a refletir sobre as potencialidades das ações de formação de professores desenvolvidas na perspectiva colaborativa.

Conforme defende Nóvoa $(1999,2007)^{14}$, os processos de formação docente devem oportunizar a reflexão coletiva sobre a própria prática, a qual permite ao professor analisar, orientado pelo próprio olhar e pelos olhares de outras pessoas, como ele tem desenvolvido seu trabalho, a fim de identificar novas possibilidades de atuação. É necessário que os professores tenham um papel importante em seu próprio processo de formação e que os estudos sejam desenvolvidos com base nas experiências docentes e nos saberes construídos a partir delas, sem que seja desconsiderada a possibilidade de serem atribuídos novos significados a uma experiência a partir das reflexões coletivas.

Percebemos a importância de desenvolver ações de formação docente na perspectiva colaborativa quando compreendemos que o homem "é a personalidade social = o conjunto de relações sociais, encarnado [de maneira singular] no indivíduo" (VIGOTSKI, 2000, p. 33, grifos do autor) e que "diferentes experiências humanas enriquecem o processo de se tornar humano" (FREITAS; MONTEIRO; CAMARGO, 2015, p. 31). Nos processos de formação em que os professores têm a oportunidade de relatar suas experiências e compartilhar suas concepções, percepções e reflexões, as possibilidades de aprendizagem e de desenvolvimento ampliam-se.

\footnotetext{
${ }^{14}$ Embora os trabalhos de Nóvoa não sejam embasados nos estudos da perspectiva histórico-cultural do desenvolvimento humano, suas propostas para a formação docente são coerentes com os fundamentos dessa perspectiva.
} 
Ao se expressar, cada um dos professores tem a oportunidade de reorganizar e, consequentemente, ressignificar seus próprios saberes e experiências; e, ao ouvir os outros, cada professor pode apropriar-se de novos conhecimentos que lhe possibilitam atribuir novos sentidos aos conhecimentos anteriores e apresentar novos olhares para as experiências já vivenciadas. Desse modo, nas relações intersubjetivas mediadas pela palavra, os professores encontram a possibilidade de vivenciar um processo de transformação, isto é, de desenvolvimento.

Esse processo é particularmente importante no contexto da educação inclusiva, que exige a superação de conceitos e práticas pedagógicas excludentes.

Os encontros na perspectiva colaborativa podem possibilitar uma reflexão pautada em fundamentos teóricos que auxiliam os professores a pensar sobre suas ações pedagógicas e modos de se olhar para o aluno com deficiência, levando-os a encontrar novos caminhos para ensinar. (FREITAS; MONTEIRO; CAMARGO, 2015, p. 35).

A mudança de concepções e olhares é essencial para que possam ser superadas "as marcas de uma construção social da deficiência pautada em estigmas e preconceitos sociais constituídos nas relações sociais" (FREITAS; MONTEIRO; CAMARGO, 2015, p. 35). A reconstrução daquilo que foi constituído socialmente passa necessariamente pela vivência de práticas sociais que promovam reflexões e questionamentos, possibilitando a apropriação de novos conhecimentos e favorecendo o autoconhecimento, conforme destaca o relato de um dos professores que participaram do encontro formativo apresentado neste artigo: "[O encontro] foi de grande valia, pois a inclusão requer conhecimento e autoconhecimento" (excerto do relato 8).

Ao analisarmos os relatos escritos por outros professores que participaram do encontro, observamos que eles destacaram a oportunidade de troca e de compartilhamento de experiências e de visões como uma das principais contribuições das atividades realizadas. Isso constitui um indício de que, segundo esses professores, as atividades de formação docente devem ser desenvolvidas na perspectiva colaborativa:

Este encontro permitiu a todos os envolvidos uma troca de experiências e visões sobre a inclusão e os desafios vividos na rotina escolar. (Excerto do relato 4 ). 
Compartilhamos visões diferentes e experiências. (Excerto do relato 9).

Todo e qualquer momento de troca de experiência, debate, criticidade ou levantamento de problemas e soluções nos faz perceber a importância que o educador desenvolve em sociedade. (Excerto do relato 10).

Os relatos transcritos indicam que os professores reconhecem a importância do outro em seu processo de formação. O compartilhamento de experiências e visões possibilita não apenas a apropriação de novos conhecimentos, mas também o "abrandamento da solidão e ansiedade de trilhar um caminho novo e desconhecido" (excerto do relato 6). Nas palavras desse relato, notamos o desejo de que a caminhada rumo à superação dos desafios enfrentados na educação inclusiva não seja solitária, o que indica a necessidade de um processo de desenvolvimento coletivo.

Propostas de formação docente direcionadas para o desenvolvimento coletivo em vez do desenvolvimento de competências individuais são coerentes com os fundamentos da perspectiva histórico-cultural, segundo os quais a educação é um processo que se dá "entre indivíduos movidos por objetivos que deverão ser coletivos" (MORETTI; MOURA, 2010, p. 353). Quando se busca, por meio da formação docente, a transformação dos professores e a consequente transformação da educação e da sociedade, não se pode propor práticas formativas centradas em competências. Essas práticas, conforme ressaltam Moretti e Moura (2010), não promovem a reflexão sobre a realidade - e, sim, a adequação a ela -, além de direcionarem o olhar de cada indivíduo apenas para si mesmo, e não para a coletividade.

Refletir sobre a formação docente exige também analisar o sentido que atribuímos ao trabalho. Segundo Moretti e Moura (2010, p. 347), quando nos fundamentamos na perspectiva histórico-cultural, é necessário que compreendamos "a atividade docente como trabalho em sua dimensão ontológica".

Nessa compreensão, o conceito de trabalho traduz-se como sendo a atividade humana intencional adequada a um fim e orientada por objetivos, por meio da qual o homem transforma a natureza e produz a si mesmo. [...] Sendo assim, o trabalho nessa concepção não é fim em si mesmo, mas é mediação para atingir um fim. (MORETTI; MOURA, 2010, p. 347). 
Notamos que, de acordo com a perspectiva histórico-cultural, o trabalho deve ser entendido como um meio capaz de proporcionar a cada um a possibilidade de transformar a si mesmo e a sociedade em que está inserido. Nessa perspectiva, portanto, o trabalho não deve ser buscado como forma de adequação à realidade, mas, sim, como meio de transformação dela.

De acordo com Engels (2005, p. 4), o trabalho "é a condição básica e fundamental de toda a vida humana. E em tal grau que, até certo ponto, podemos afirmar que o trabalho criou o próprio homem". A afirmação do autor permite-nos compreender que, assim como o trabalho possibilitou a diferenciação do ser humano em relação aos animais, ele promove o desenvolvimento do que é próprio do homem em todos os tempos, permitindo a transformação não apenas da natureza, mas também das pessoas.

Quando compreendemos o trabalho nessa perspectiva, passamos a considerar o desenvolvimento profissional e o desenvolvimento humano como indissociáveis, assim como trabalho e vida são indissociáveis. Passamos a entender a atividade docente - assim como toda forma de trabalho - como algo que integra a constituição do indivíduo. Desse modo, toda transformação pela qual o indivíduo passa reflete em sua atividade profissional, assim como as transformações mais diretamente relacionadas à sua profissão também impactam as outras dimensões de sua vida. Essa inter-relação entre desenvolvimento profissional e desenvolvimento humano pode ser notada no relato de um dos professores que participaram da ação formativa descrita neste artigo, segundo o qual o encontro possibilitou "um enriquecimento profissional e pessoal a todos" (excerto do relato 4).

Esse modo de compreender o trabalho realça a importância de explorarmos, nas ações de formação de professores, as três dimensões da atividade docente apresentadas por Fanfani (2007). Ao buscarmos possibilitar que os professores se desenvolvam não apenas na dimensão técnico-instrumental, mas também nas dimensões afetiva e política, estreitamos as relações entre o desenvolvimento profissional e o desenvolvimento humano, além de destacarmos o papel do trabalho como meio de transformação, uma vez que a dimensão política da atividade docente se caracteriza pelo "compromiso social y político con las causas de los derechos humanos universales"15 (FANFANI, 2007, p. 348).

\footnotetext{
${ }^{15}$ [...] "compromisso social e político com as causas dos direitos humanos universais" (tradução nossa).
} 
As dimensões exploradas nas ações de formação docente estão relacionadas ao tipo de indivíduo que queremos formar. Assim como Moretti e Moura (2010, p. 353), "preferimos ficar com a opção da formação de um homem histórico, humanizado por meio de um processo de apropriação cultural. Essa cultura, construída socialmente, implica conhecimentos e técnicas, mas também artes, valores, posturas".

Notamos que, por meio de palavras diferentes, Moretti e Moura (2010) expressam ideias semelhantes às de Fanfani (2007), realçando as diversas dimensões que constituem o que é próprio do ser humano. Os autores reforçam, desse modo, a indissociabilidade entre desenvolvimento profissional e desenvolvimento humano.

Os relatos docentes analisados por nós indicam que os professores perceberam que seu processo de desenvolvimento está relacionado não apenas a conhecimentos e técnicas. Segundo os professores, entre as contribuições do encontro de que participaram está o fato de ele ter possibilitado compreender que:

[...] às vezes, para que um aluno aprenda, vou precisar ensinar primeiro hábitos de higiene, vou precisar dar alguns bons conselhos, amar, respeitar e acolher. (Excerto do relato 2).

Incluir é acolher. É me colocar no lugar do outro. (Excerto do relato 7).

Amor, dedicação são palavras-chave para que a inclusão aconteça. (Excerto do relato 8).

Devemos trabalhar e nos empenhar em ajudar nossos alunos com muito carinho para que possamos atingir nossas metas. (Excerto do relato 14).

Esses excertos indicam que, nas propostas de formação de professores, é importante que também haja reflexões sobre as posturas e os afetos envolvidos na atuação docente no contexto da educação inclusiva. Quando se busca formar um indivíduo humanizado, explorando-se as diferentes dimensões que caracterizam o humano, aquele que participa do processo formativo tem a oportunidade de sentir-se transformado: "Acredito que hoje vou pensar melhor, de maneira mais humana, incluir meus alunos; não que eu não faça isso, mas com maior dedicação" (excerto do relato 8). Cumpre-se, assim, o propósito da formação docente, que é proporcionar o desenvolvimento dos professores, a fim de que eles possam contribuir para o desenvolvimento de seus alunos. 
Notamos também indícios de que o encontro formativo realizado atingiu os objetivos esperados ao encontrarmos, nos relatos dos professores, sinais de que, por meio das reflexões desenvolvidas, eles passaram a perceber sua responsabilidade em relação à aprendizagem e ao desenvolvimento de seus alunos e a enxergar seu trabalho como um meio capaz de transformar vidas:

Nesse momento, pude refletir ainda mais, sobre a inclusão: de que não temos uma receita, e é, sim, um trabalho de formiguinha, que aos poucos vamos conseguir mudar algumas histórias! (Excerto do relato 3 ).

O momento trouxe uma reflexão sobre nossa situação ao receber e incluir cada aluno em nossa escola. Pois enquanto estiverem em nossa companhia, a responsabilidade será nossa (ou melhor, MINHA!). (Excerto do relato 7 ).

Não podemos também esquecer que devemos, cada vez mais, nos aperfeiçoar em prol desses alunos. (Excerto do relato 14).

A tomada de consciência sobre o potencial de transformação do trabalho docente encoraja os professores a acreditar que os desafios da educação inclusiva podem ser superados e a assumir sua responsabilidade nesse processo. Esse encorajamento é fortalecido pela sensação de pertencimento a um grupo que tem objetivos em comum, sensação essa promovida pelo compartilhamento de experiências e reflexões. Tudo isso é essencial para que possamos avançar no processo de construção de uma educação capaz de garantir a aprendizagem e o desenvolvimento de todos os alunos, pois, "mesmo com tantas limitações, nunca devemos desistir. [É preciso] sonhar sempre com um mundo melhor" (excerto do relato 9).

\section{Considerações finais}

Refletimos, neste artigo, sobre o desenvolvimento profissional e humano de professores à luz da perspectiva histórico-cultural a partir de uma experiência formativa com foco na educação inclusiva realizada com docentes da educação básica. Ao longo do artigo, procuramos entrelaçar nossas reflexões à análise dos relatos escritos pelos professores que participaram da referida experiência. Identificamos nesses relatos indícios 
de que o encontro realizado, ao favorecer as relações intersubjetivas e explorar diferentes dimensões do trabalho docente, mobilizou o processo de desenvolvimento dos professores.

Considerando os quatro planos genéticos em que, segundo a perspectiva históricocultural, se dá o desenvolvimento humano, compreendemos que na fase adulta também ocorre desenvolvimento, isto é, transformação. Analisando mais especificamente o desenvolvimento de professores por meio de ações formativas, refletimos sobre a importância das relações intersubjetivas mediadas por instrumentos técnico-semióticos, identificando as potencialidades das práticas de formação desenvolvidas na perspectiva colaborativa.

Essas práticas destacam-se por possibilitarem a reelaboração de conceitos e a ressignificação de saberes e experiências, sendo esses processos extremamente importantes no contexto da educação inclusiva, que exige mudança de concepções e de olhares. Além disso, as ações de formação docente na perspectiva colaborativa procuram promover o desenvolvimento coletivo, essencial quando se almeja a construção de uma nova educação e de uma nova sociedade.

Refletimos ainda sobre a importância de compreendermos a atividade docente como trabalho em sua dimensão ontológica, isto é, não como um fim em si mesmo, mas como um meio para atingir um fim e como algo indissociável da própria vida. Desse modo, realçamos a inter-relação entre desenvolvimento profissional e desenvolvimento humano, destacando que a formação de professores deve envolver não apenas a dimensão técnicoinstrumental, mas também as dimensões afetiva e política, de modo que sejam explorados, além de conhecimentos e técnicas, valores, posturas, entre outros elementos que constituem o que é próprio do ser humano.

Não podemos nos esquecer de que, como afirma Vygotski (2012), o desenvolvimento é sempre um processo dialético, complexo, não linear, marcado por evolução e involução. Ainda assim, observar indícios da mobilização de um processo de desenvolvimento de professores promovida por uma ação formativa é algo muito propositivo, sobretudo no contexto da educação inclusiva, que tem mostrado a necessidade de transformação dos docentes. É preciso que haja essa transformação para que ocorram mudanças nas práticas pedagógicas e nos olhares sobre as pessoas com deficiência, de 
modo que passem a ser oferecidas a todos os alunos oportunidades de desenvolvimento cultural.

\section{Referências}

BRASIL. Lei n 9.394, de 20 de dezembro de 1996. Estabelece as diretrizes e bases da educação nacional. Brasília: Presidência da República, 1996. Disponível em: <http://www.planalto.gov.br/ccivil_03/leis/L9394.htm>. Acesso em: 6 fev. 2021.

BRASIL. Ministério da Educação. Secretaria de Educação Especial. Política Nacional de Educação Especial na Perspectiva da Educação Inclusiva. Brasília: Ministério da Educação, 2008. Disponível em: http://portal.mec.gov.br/index.php?option=com_docman\&view= download\&alias=1669o-politica-nacional-de-educacao-especial-na-perspectiva-daeducacao-inclusiva-05122014\&ltemid=30192. Acesso em: 6 fev. 2021.

DAINEZ, D.; SMOLKA, A. L. B. A função social da escola em discussão, sob a perspectiva da educação inclusiva. Educação e Pesquisa, São Paulo, v. 45, p. 1-18, 2019. Disponível em: https://www.scielo.br/pdf/ep//v45/1517-9702-ep-45-e187853.pdf. Acesso em: 6 fev. 2021.

ENGELS, F. Sobre o papel do trabalho na transformação do macaco em homem. [S.l.]: Ridendo Castigat Mores, 2005. Disponível em: http://www.ebooksbrasil.org/adobeebook/ macaco.pdf. Acesso em: 3 jul. 2020.

FANFANI, E. T. Consideraciones sociológicas sobre profesionalización docente. Educação \& Sociedade, Campinas, v. 28, n. 99, p. 335-353, maio/ago. 2007. Disponível em: http://www. scielo.br/pdf/es/v28ng9/ao3v2899.pdf. Acesso em: 21 mar. 2020.

FREITAS, A. P. de; MONTEIRO, M. I. B. "Olhar" e pensar o ensino para alunos com deficiência: os saberes produzidos em contexto colaborativo. Revista Lusófona de Educação, Lisboa, v. 34, n. 34, p. 143-159, 2016. Disponível em: https://revistas.ulusofona. pt/index.php/rleducacao/article/view/5821. Acesso em: 11 jul. 2020.

FREITAS, A. P. de; MONTEIRO, M. I. B.; CAMARGO, E. A. A. Contradições no/do cotidiano escolar: professores e alunos com deficiência diante do ensino na diversidade. Horizontes, Itatiba, v. 33, n. 2, p. 27-36, jul./dez. 2015. Disponível em: https://revistahorizontes.usf.edu. br/horizontes/article/view/245/91. Acesso em: 9 jul. 2020.

GARCIA, R. M. C. Política de educação especial na perspectiva inclusiva e a formação docente no Brasil. Revista Brasileira de Educação, Rio de Janeiro, v. 18, n. 52, p. 101-119, jan./mar. 2013. Disponível em: https://revistas.ulusofona.pt/index.php/rleducacao/article/ view/5821. Acesso em: 18 abr. 2020.

GARCIA, R. M. C. Educação especial na perspectiva inclusiva: determinantes econômicos e políticos. Comunicações, Piracicaba, v. 23, n. 3, p. 7-26, 2016. Número Especial. Disponível em: https://www.metodista.br/revistas/revistas-unimep/index.php/comunicacoes/article/ 
view/2938/1833. Acesso em: 19 abr. 2020.

GATTI, B. A. Formação de professores, complexidade e trabalho docente. Diálogo

Educacional, Curitiba, v. 17, n. 53, p. 721-737, 2017. Disponível em: https://periodicos.pucpr. br/index.php/dialogoeducacional/article/view/8429/17739. Acesso em: 20 mar. 2020.

KASSAR, M. de C. M. A formação de professores para a educação inclusiva e os possíveis impactos na escolarização de alunos com deficiências. Cadernos Cedes, Campinas, v. 34, n. 93, p. 207-224, maio/ago. 2014. Disponível em: https://www.scielo.br/pdf/ccedes/v34n93/ 0101-3262-ccedes-34-93-0207.pdf. Acesso em: 18 abr. 2020.

LAPLANE, A. L. F. de. Condições para o ingresso e permanência de alunos com deficiência na escola. Cadernos Cedes, Campinas, v. 34, n. 93, p. 191-205, maio/ago. 2014. Disponível em: https://www.scielo.br/pdf/ccedes/v34n93/0101-3262-ccedes-34-93-0191.pdf. Acesso em: 19 abr. 2020.

MICHELS, M. H. O que há de novo na formação de professores para a educação especial? Revista Educação Especial, Santa Maria, v. 24, n. 40, p. 219-232, maio/ago. 2011. Disponível em: https://periodicos.ufsm.br/educacaoespecial/article/view/2668/2440. Acesso em: 17 abr. 2020.

MORETTI, V. D.; MOURA, M. O. de. A formação docente na perspectiva histórico-cultural: em busca da superação da competência individual. Revista Psicologia Política, São Paulo, v. 10, n. 20, p. 345-361, jul./dez. 2010. Disponível em: http://pepsic.bvsalud.org/pdf/rpp/v10 n2o/v1on20a12.pdf. Acesso em: 8 jul. 2020.

MOURA, E. A. et al. Os planos genéticos do desenvolvimento humano: a contribuição de Vigotski. Revista Ciências Humanas, Taubaté, v. 9, n. 1, p. 106-114, jun. 2016. Disponível em: https://www.rchunitau.com.br/index.php/rch/article/view/298/189. Acesso em: 17 jul. 2020.

NÓVOA, A. Os professores na virada do milênio: do excesso dos discursos à pobreza das práticas. 1999. Disponível em: repositorio.ul.pt/bitstream/10451/690/1/21136_151799702_. pdf. Acesso em: 20 mar. 2020.

NÓVOA, A. O regresso dos professores. In: CONFERENCE ON TEACHER PROFESSIONAL DEVELOPMENT FOR THE QUALITY AND EQUITY OF LIFELONG LEARNING, 2007, Lisboa. Proceedings [...]. Lisboa: Universidade de Lisboa, 2007. p. 1-14.

OLIVEIRA, M. K. de. Ciclos de vida: algumas questões sobre a psicologia do adulto. Educação e Pesquisa, São Paulo, v. 30, n. 2, p. 211-229, maio/ago. 2004. Disponível em: https://www.scielo.br/pdf/ep/v3on2/v3onza02.pdf. Acesso em: 29 jun. 2020.

PADILHA, A. M. L. Alunos com deficiência intelectual: reflexões sobre o conceito de desenvolvimento das funções psíquicas superiores e o papel da educação escolar na perspectiva histórico-cultural da escola de Lev Vigotski. Horizontes, Itatiba, v. 36, n. 3, p. 62-73, set./dez. 2018. Disponível em: https://revistahorizontes.usf.edu.br/horizontes/article/ 
view/681/304. Acesso em: 6 fev. 2021.

PINO, A. Semiótica e cognição na perspectiva histórico-cultural. Temas em Psicologia, Ribeirão Preto, v. 3, n. 2, p. 31-40, ago. 1995. Disponível em: http://pepsic.bvsalud.org/pdf/ tp/v3n2/v3n2a05.pdf. Acesso em: 10 jul. 2020.

PINO, A. A análise semiótica. In: PINO, A. As marcas do humano: as origens da constituição cultural da criança na perspectiva de Lev S. Vigotski. São Paulo: Cortez, 2005. p. 175-194.

PLETSCH, M. D. Educação especial e inclusão escolar: políticas, práticas curriculares e processos de ensino e aprendizagem. Poíesis Pedagógica, Catalão, v. 12, n. 1, p. 7-26, jan./jun. 2014. Disponível em: http:// www.revistas.ufg.br/poiesis/article/view/31204/16802. Acesso em: 6 fev.2021.

SMOLKA, A. L. B. Sobre significação e sentido: uma contribuição à proposta de Rede de Significações. In: ROSSETTI-FERREIRA, M. C. et al. (org.). Rede de Significações e o estudo do desenvolvimento humano. Porto Alegre: Artmed, 2004. p. 35-49.

VIGOTSKI, L. S. Psicologia concreta do homem. Educação \& Sociedade, Campinas, ano 21, n. 71, p. 23-44, jul. 2000. Disponível em: http://www.scielo.br/pdf/es/v21n71/a02v2171.pdf. Acesso em: 3 jul. 2020.

VIGOTSKI, L. S. Teoria e método em psicologia. 3. ed. São Paulo: Martins Fontes, 2004.

VYGOTSKI, L. S. Obras escogidas III: problemas del desarrollo de la psique. Madrid:

Machado Grupo de Distribución, 2012.

WERTSCH, J. V. Vygotsky y la formación social de la mente. Barcelona: Paidós, 1988.

\footnotetext{
' Doutoranda em Educação pela Universidade São Francisco (USF) e docente da Universidade Federal de Itajubá (Unifei). Desenvolve sua pesquisa de doutorado com financiamento da Coordenação de Aperfeiçoamento de Pessoal de Nível Superior (Capes).

E-mail: cibeleunifei@yahoo.com.br

ii Doutora em Educação pela Universidade Estadual de Campinas (Unicamp) e docente do Programa de PósGraduação Stricto Sensu em Educação da Universidade São Francisco (USF). Bolsista Produtividade CNPq nível 2.

E-mail: freitas.apde@gmail.com
} 